\title{
Medical student participation in community-based experiential learning: reflections from first exposure to making the diagnosis
}

\author{
Cameron Da, Wolvaardt L'b , Van Rooyen $\mathrm{M}^{\mathrm{a}}$, Hugo Ja, Blitz Ja, Bergh A-M ${ }^{\mathrm{c}}$ \\ aDepartment of Family Medicine, University of Pretoria

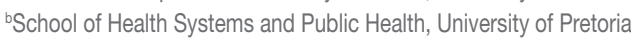 \\ 'MRC Unit for Maternal and Infant Health Care Strategies, University of Pretoria \\ Correspondence to: David Cameron, e-mail: david.cameron@up.ac.za \\ Keywords: service learning, reflection, primary care, educational diagnosis
}

\begin{abstract}
Background: Fifth-year medical students from the University of Pretoria participated in a four-week rotation in the primary care clinics of a large metropolitan centre. An academic service-learning (ASL) approach was introduced into this rotation to improve the integration of theoretical learning and clinical practice through relevant community service and structured reflection.
\end{abstract}

Methods: Students wrote semi-structured reflective journals as a means to gaining greater insight into their learning experiences. These reflections were analysed qualitatively with a view to improving the community-based curriculum.

Results: Four major themes were identified: expectations and the reality of primary care; service and learning; becoming a doctor; and making a difference.

Conclusion: While students gained a deeper insight into their development as clinicians, using an ASL approach also assisted the faculty in making an informed educational diagnosis of the curriculum.

(P) Peer reviewed. (Submitted: 2010-10-01, Accepted: 2010-12-21). ๑ SAAFP

S Afr Fam Pract 2011;53(4):373-379

\section{Introduction}

A significant part of medical students' training has traditionally involved rotations through various specialty disciplines in academic and district hospitals. With the gradual shift of health care from in-patient to ambulatory care, more training is taking place within community settings. $^{1-4}$ When faced with the responsibility of making a diagnosis and recommending treatment, medical students have to deal with many challenges, while grappling with the complexity of the consultation and integrating their previous theoretical training. ${ }^{5}$ When they face this responsibility for the first time in a community-based clinic, there is the added challenge of an unfamiliar primary healthcare system. ${ }^{6}$

Teaching staff face similar challenges of complexity and uncertainty ${ }^{7}$ as they attempt to shape the curriculum for a community-based rotation into one that is more appropriate for meeting the demands of the health system. ${ }^{8-10}$ Medical students at the University of Pretoria participate in a Health and Health Systems module in the first half of their fifth year. Previously, it included a limited community-based component in the primary care clinics of a large metropolitan centre. In 2008, the module was restructured along the lines of an academic service-learning (ASL) approach. ${ }^{11}$
The recommendations of the Higher Education Quality Committee $^{12}$ and the Higher Education Act $(1997)^{13}$ established community engagement as an integral part of higher education in South Africa. This laid the foundation for the development of ASL in this country. ${ }^{12}$ ASL is a theoretical teaching framework that intentionally integrates academic learning and relevant community service. The latter is used to enhance academic learning, while academic learning informs meaningful service. ${ }^{14-20}$ In the complex situations that arise in the workplace, students experience situations that they do not understand and for which classroom-based teaching does not adequately prepare them. Rather than provide them with glib answers, the ASL approach is to encourage students to critically examine their own knowledge and what they have been taught in the light of the reality of their working environment. ${ }^{21}$ This structured reflection ${ }^{22-24}$ helps them to acquire new health concepts, new attitudes to their future careers as health professionals, and a new understanding of the health needs of their community. ${ }^{19,23}$ The combination of active learning and critical thinking encourages personal and professional growth, a deeper understanding of complex social issues and a growing sense of social responsibility. ${ }^{18-21,25}$ The intentional 
integration of all these components sets ASL apart from mere workplace experience within a community setting and "qualitatively changes the norms and relationships in the teaching-learning process"..$^{18}$ Learning shifts from a competitive process focused on individual success to collaboration between medical student, healthcare provider and patient, in which all give and receive. ${ }^{26}$

In our "new" module, students were required to write semistructured reflective journals to assess the impact of their experiences. This paper focuses on these written reflections and also alludes to how the findings informed the further educational diagnosis of the module and adjustments made to the overall curriculum in primary health care.

\section{The "new" module}

The new service learning module, Health and Health Systems, was presented for the first time from JanuaryMay 2008. The whole class $(n=208)$ was divided into four groups of approximately 50 students each, and each group completed a four-week rotation. During the first week of the rotation, students were orientated to the block and prepared for service learning in the clinics. Management of the common conditions and a wide variety of clinical and interpersonal skills were reviewed. All students had an opportunity to demonstrate and teach a clinical skill to their peers and to receive peer feedback on their teaching style.

Following this week of preparation, the students were allocated to one of 11 public sector clinics. These urban and peri-urban clinics, which have a long-standing service partnership with the university, offer a full range of primary health care services. Clinics were chosen so that students could gain experience with patients with undifferentiated problems that had not been adequately resolved in terms of their exact nature, or degree of severity. Prior to this module, the students' clinical exposure had been mainly in tertiary or secondary academic hospitals in various specialist disciplines. In these hospitals, the role of junior students is to carry out ward tasks such as drawing blood, or replacing an intravenous line, rather than being actively involved in the decision making about the diagnosis or management of patients. However, in the primary health care context, students are expected to handle "whatever comes through the door". As the first point of contact, they get an opportunity to formulate their own assessment of the patient's problem. This enables them to integrate all their prior knowledge and gain confidence in their clinical reasoning skills. ${ }^{27-29}$

Primary health care clinics in South Africa are nurse managed and most of the clinical work is done by nurses trained in consultation skills. These nurse practitioners work according to clearly defined protocols for primary care, set out in Standard treatment guidelines and essential medicines for South Africa. ${ }^{30}$ In the smaller clinics, a doctor visits regularly and provides a back-up consultation service. At larger clinics, there are full-time doctors. The relationship between the medical and nursing staff is less hierarchical and the clinic setting demands a willingness to work in a team.

\section{Critical reflections}

With reflection being a central feature of service learning, students were introduced to the three-stage model of Toole and Toole ${ }^{31}$ In this model, the questions for reflecting upon the experience can be summarised as "What?", "So what?", and "Now what?". The "What" questions focused on the experience; on what actually happened. The "So what?" questions encouraged students to evaluate the experience and to re-examine their theoretical knowledge in the light of that experience. The "Now what?" questions challenged them to consider how the experience had changed their perceptions and future plans.

For the individual written reflective reports, students were asked to reflect before, during, and after the clinic visits on what they had learnt, how they had learnt, what their thoughts were about the context, and how they felt about their experiences. These reports were assessed with a rubric, and each student received personal feedback.

At the end of each week, they participated in a group reflection session. They were divided into three groups, each facilitated by a faculty member from the Department of Family Medicine. The sessions lasted about 45 minutes and were deliberately unstructured so as to encourage the diversity of student voices. In these sessions, students could raise uncertainties and share the dilemmas they experienced in medical practice. This presented opportunities for facilitators to help students to make sense of the discrepancies between practice and theory. ${ }^{23}$ Any significant events from the past week could be discussed. Students were encouraged to re-examine their assumptions, to explore the issues from various perspectives and to consider alternative ways of resolving their dilemmas. These meetings served to role model reflective practice. ${ }^{22,23,32,33}$ One student commented in the formal feedback questionnaire that: "... the reflection sessions helped to process the experiences I had, and I think that every rotation should have them". Another commented on these sessions in her reflective journal as follows: "The total honesty of the students and the way that Prof $X$ listened and understood our problems really touched my heart. There was no beating around the bush with any of the facts or feelings. I really felt that we were 
making progress towards a bigger goal with this attitude. I also realised that many of my fellow students were also experiencing the same feelings about some issues that I have been too scared to say out loud. This really bonded us together as a group".

\section{Methods}

The study was approved by the research ethics committee of the University of Pretoria (Protocol 11/2007). One hundred and fifty-four (154) students in the cohort of 208 provided written, informed consent for their written reflections to be used as part of the study. A manual analysis of the reflections was undertaken as electronic copies were unavailable. In order to cope with the large number of texts, the data analysis was performed in a staggered manner.

An initial in-depth analysis of 33 documents was conducted by one of the researchers (AMB) using open coding for identifying possible categories with codes and subcodes. ${ }^{34}$ Any deviant cases and striking narratives were also noted. At this stage, it appeared as if data saturation ${ }^{35}$ had been reached. The findings from this analysis were then discussed at a meeting where all the authors were present. After discussion at this meeting, two further categories were added.

The identified categories were then divided among the researchers for further in-depth analysis of each, using copies of the original documents on which the initial analysis had been done. The analyses of the individual researchers were then distributed among all the team members and interpretations were discussed at further meetings. A process that resembles axial coding ${ }^{34}$ was followed, and themes and patterns were abstracted at a higher level of analysis.

To ensure that the sample sufficiently reflected the diversity of the student cohort and to confirm data saturation, a further 17 reflections were then analysed in depth by a researcher (AMB). The rest of the process was the same as for the initial analysis. One team member (DC) then scrutinised the rest of the documents (104) for further confirmation of data saturation and the feasibility of the group interpretations. The findings were compared with interpretations emerging from the feedback of other role players (clinic staff and mentors) and the official student feedback on the module as a means of triangulation. No additional insights came to light. Researcher triangulation was achieved by this rigorous process of tiered and peer-reviewed data analysis.

\section{Findings}

The findings are structured around four main themes (expectations and the reality of primary care, service and learning, becoming a doctor, and making a difference), each with subthemes that emerged from the student reflections. Expectations and the reality of primary care encompasses students' emotions, reception at clinics and lack of resources as subthemes. Service and learning was divided into learning from others, experiential learning and the place of reflection in learning. Becoming a doctor relates to the consultation, interpersonal relationships and gaining confidence. Making a difference refers to making a difference at the clinic and for patients. Each of the subthemes is discussed in detail, and illustrative examples are provided in support.

\section{Expectations and the reality of primary health care}

Students anticipated that this first exposure to working at a primary healthcare clinic would allow them to put theory into practice, as they tried to integrate their clinical skills and knowledge with the challenges of dealing with people presenting with a wide range of health problems. Towards the end of the rotation, one student wrote that: "One of the major things this rotation has done for me is open my eyes to the reality of public health".

\section{"A rollercoaster of emotions"}

Prior to going to the clinics, students were requested to reflect on their expectations for the rotation. Their emotions fluctuated between "excitement" and "curiosity", to "uncertainty", "fear", "apprehension" and "trepidation". "I was excited, but also pretty overwhelmed," said one. Another described the experience as "a rollercoaster of emotions".

This plethora of emotions was fuelled by fear of the unfamiliar, the students' own concerns about medical care outside of academic institutions, and feedback from past students. Uppermost in their minds was the feeling of uncertainty about what was expected from them, as the structure of the rotation had been completely changed from that of the previous year.

\section{Reception at the clinics}

Students described the clinic nursing staff as accommodating, friendly and helpful. Staff made a special effort to orientate and integrate them into their normal routines. This was clearly a surprise for some students who had previously had negative experiences with hospital nursing staff. "It was most surprising to me how helpful and the friendly the nurses are. They take pride in the fact that they contribute to our education," was one comment. 


\section{Lack of resources}

In some clinics, lack of functioning diagnostic equipment, temporary shortages of specific drugs, power cuts, lack of space, the pressure of coping with many patients and the lack of on-site X-ray and laboratory services caused much frustration: “... the lack of functioning equipment was very frustrating. The ophthalmoscope used on a diabetic patient was not working and this compromised patient care".

While some students responded with irritation, others adopted a more philosophical approach: "I was also able to see what it takes to keep a clinic functioning successfully and also to witness first hand all the challenges they face on a daily basis. Seeing this made me realise why it is often easy for people to assume a negative attitude and blame the system. However, I was pleasantly surprised to see how committed most of the clinic staff is and that their enthusiasm for their jobs keeps them going, even while facing difficult challenges".

Students used this learning opportunity to challenge and revise their opinions of nurses in general. They could experience first-hand the range of complex organisational challenges that primary health care staff encounter as normal.

\section{Service and learning}

Integrating service and learning is far from simple. The learning outcome needs to be synergistic; each part needs to inform and transform the other into an integrated whole that exceeds their mere conjoining. ${ }^{18}$

\section{Learning from others}

In the primary care clinics, nurses take on many of the functions of a clinician. While students soon realised that they could learn many things from the nurses, their learning extended beyond knowledge about the management of illness to include new attitudes and improved relationships. "I think it has opened my eyes to the amount of work put in by sisters in the primary health setting. They are like doctors in their clinics and are able to handle the patients with such excellence. It has given me a lot of respect for them and made me realise that I can learn a lot from them. This changes my attitude towards nursing staff," was a comment.

Teamwork ("Two heads are better than one") gave students the opportunity to become comfortably aware of their own limitations, both clinical and personal. "I have learnt that every person is an individual with strengths and weaknesses," said a student. "People have different personalities and therefore react to situations differently. This gives an understanding of why they do the things they do. No matter how different we all are, we can work together as a team. It is important to consider people's feelings, try to understand their point of view and not just treat them as objects. I now have a better idea of my limitations."

A key breakthrough in students' understanding was the realisation that teamwork is beneficial, not only as a mechanism through which to confirm their own thoughts about diagnosis and treatment options, but also as a source of learning. At the clinic, the value of teamwork was foregrounded for students as they witnessed daily evidence thereof and the importance of becoming a member of that team. This encouraging atmosphere and mutual support created a platform for students from which they could launch their own learning. Peer learning was not limited to enhancing medical knowledge or skills. Rather students welcomed the opportunity to discuss their experiences and feelings with their class mates. There were also instances where a student did not mind doing something because it led to greater group happiness.

\section{Experiential learning}

Workplace experience enabled students to re-examine the theoretical teaching they had received in the classroom against the reality of the workplace. At times, that reality challenged them to re-examine their views and opinions. "I have always assumed that the less serious diseases were less important and that they did not really deserve our time and efforts as much as the more seriously ill patients... I see that my focus was too much on curing disease and not enough on caring for the patient," was a comment.

Experience by itself does not necessarily promote learning. ${ }^{15}$ But experience can provide the "raw material for learning". ${ }^{36}$ Experiential learning also reinforces knowledge and aids memory: "I have learned many things that were long forgotten and think that because of the practical work l've been able to do, the knowledge will remain with me for many years to come".

In addition to dealing with the numerous clinical problems that may present at primary care level, the clinician requires a wide range of practical skills. Exposure to clinical work in these settings helped students to gain a new perspective on the purpose of learning. Studying ceased to be merely a matter of memorising facts and passing tests; it became directed at becoming a competent clinician. "I came to the realisation that this is how family medicine differs. Learning is not just to gain enough knowledge to be able to pass a test. Gaining knowledge means that you can now actually know it and can put it into practice. I now attach more importance to learning," said one student. 
At times students encountered situations in the workplace where things were done very differently from what they were taught. "I have noticed that things are not always done according to the book and that many bad habits are practiced." Understandably this reality evoked strong responses.

\section{The place of reflection in learning}

As part of their reflections on their consultations, students began to understand the way in which they gathered information, what thinking processes they followed to solve problems, and how they made decisions. This reflective process helped them to understand why they had missed a correct diagnosis: "I wrote a retrospective analysis of my consultation afterwards and was shocked at how much I had left out...". The process also helped students to understand how they could improve their diagnostic abilities in the future. "I have learned that I can go into tremendous unnecessary detail regarding a patient's history. This usually sidetracks me from the main problem. I think I must learn to ask myself what the relevance of this piece of information is and I must try to focus on the most important things...."

Students learnt a great deal about themselves and the effect of their own attitude on patient care. One student indicated: "... my own attitude determines the way in which a patient perceives and responds to me to a great extent", while another said: "I have learned that I can be very focused and effective, but it depends on my motivation. I tend to be ineffective when I am tired and in a bad mood, but if I adjust my mindset to make the most of an opportunity, I usually perform much better".

Reflection has been recognised as essential to gaining the full benefit arising from dealing with the complex problems that occur in professional practice. $22-24,31-33$ Reflection enabled the students to interpret and integrate experience with existing knowledge and to make the necessary adjustments so that complex problems could be managed with increasing competence.

\section{Taking responsibility for own learning}

Practical experience helped students to realise the need to take responsibility for their own learning. They expressed themselves in a variety of ways:

- "I have decided to create opportunities for myself and not just to wait for them to come along."

- "I could have been more proactive, instead of constantly being scared or frustrated."

- "I discovered that there is a lot that you can learn by trying to do things on your own, but that we are still inexperienced."
Students moved through ever-increasing cycles from the safe, but lonely, learning in the classroom, to the uncertain and messy terrain of interdependent learning in real-life situations. Students' vulnerable state of flux and mandatory introspection was characterised by the initial rollercoaster of emotions that stabilised over the course of the rotation and set in motion the shift to becoming a reflective doctor.

\section{Becoming a doctor}

Students enjoyed the many new roles that they were able to play in the clinics, working independently as a clinician, or cooperating as a member of the clinic team. Their enthusiasm about engaging with all the opportunities that the rotation presented was clear. "I did not want to stand on the sidelines and provide minor help; I wanted to be the one providing the services myself. Thankfully I was given this opportunity, albeit in a controlled setting with a doctor and a nurse not too far away," said one.

It was this particular opportunity to examine and treat patients that had the most impact on students: "I felt terrified holding the first file and not knowing where to start and what to do. It helped just to stay calm, take a moment and organise my thoughts and then address the patient. Working in a stepwise manner helped me to get a history from the patient".

Other comments were: "It was a challenge to be left completely on your own with a patient, but still it was a great opportunity to learn and practise the role of being a healthcare worker. I had a responsibility towards patients that I have never had before. They expected of us to take on the role of a doctor".

"Consulting without a doctor's guidance really helped to build my confidence. It also made me realise that I am very capable of making a diagnosis for myself and that I have actually learnt quite a lot over the past four years. I liked the fact that every patient presented with a completely different problem from a completely different area of medicine. This added to the challenge of acquiring the necessary information, and doing the appropriate physical examinations and special investigations."

In theoretical teaching, medical conditions are often presented in the condensed form of the typical example. The vagueness of reality was puzzling to many students. "I was frustrated by the fact that it was quite difficult to diagnose conditions when patients presented with minor vague symptoms and no clinical signs."

What may start off as a simple consultation can bring to the surface the complexity of interpersonal relations. Some patients were perceived to be "not always honest and open", 
to refuse "to cooperate and listen", and to be "very noncompliant and ungrateful", leaving some students feeling "helpless with some patients' ignorance of their condition".

Gaining a deeper understanding of the consultation process helped students to approach the consultation more holistically, thus enabling them to reach an outcome that was mutually beneficial. This is how students expressed themselves:

- "Establishing good, open relationships with your patients will not only leave them feeling happier and more satisfied, but will also aid you in making diagnoses."

- "I've learned to be more patient-driven and less timedriven and to see the patient more in context than just as a person with a disease that has a specific treatment."

- "I have more respect for patients' personal and environmental problems because of what l've experienced."

Ultimately the gain in confidence that the students experienced in working in the primary healthcare clinics confirmed their choice of career. "During this time, I learnt a lot about myself and have realised that I wouldn't want to do anything else than medicine."

This crystallisation of the students' becoming doctors allowed other features to surface, namely a sense of urgency; the growing realisation that they can make a difference.

\section{Making a difference}

ASL changes the context, as well as the content of learning. There is a shift from passively receiving to actively engaging in the discovery of knowledge. But there is also the opportunity to contribute to the wellbeing of others. Our students had similar experiences.

\section{Making a difference at the clinic}

Working in the primary care clinics gave students a real sense of achievement and a clearer understanding of primary care needs. "I often felt that while I was there to learn, I was also providing a service. I helped patients with their problems, and I took some of the workload off the staff at the clinic (although they often helped me too)."

\section{Making a difference for patients}

"Seeing patients in a clinic felt much more natural than seeing them in hospital. In a sense I became part of their lives." The experience of managing a sick patient and seeing positive results was also a great encouragement to the students. "It felt reassuring to know that I made a difference in one patient's life. Even when I felt lost somewhere between four years of study and actually having to apply everything to patients, I realised that I know more than I give myself credit for. I still have a long way to go, but l'm getting somewhere."

The clinics provided both the physical and professional space for the emergence of students' professional identities, well clear of the restrictive influence of the established professional identities of their clinical tutors and lecturers in the hospital settings. This freedom allowed them to experience both an expansion of identity through their reawakened sense of urgency, as well as an understanding that they can tolerate working with others and that their learning and practice are also enhanced by this collaboration. Complex, often conflicting situations, allowed students the opportunity to compare what "should be" with what really "is", and come to an aspirational sense of what "could be" through their participation. These findings correlate well with both local and international literature on the unique value of exposing medical students to primary health care in community settings. ${ }^{27-29}$

\section{Conclusion}

The student reflections give ample evidence of the numerous benefits of framing the new module from an ASL perspective, integrating academic learning and relevant community service. Students encountered limited resources and the need to rapidly establish effective working relationships with the clinic-based nurses.

Ambulatory patients often presented with ill-defined problems and few definite clinical signs, adding to the complexity of the challenge. From the structured reflections, it was also clear that the encounter with the challenges and complexities of working in primary health care settings changed perceptions about learning and encouraged active learning and critical thinking. There was also a better understanding of the patients' social context and a deeper sense of social responsibility. At the same time, students reflected on their personal and professional development and the increased professional confidence and improved clinical skill that accompanied their exposure to experiential learning in this community-based rotation.

Our intervention had a number of limitations. Only certain aspects of ASL were addressed and the partnership with the community, beyond the health professionals and the patients in the primary care clinics, remains largely unexplored.

However, the new module and the students' reflections also challenged the faculty to revisit its own assumptions about teaching and learning and to reflect on how to use 
this study's findings to inform further improvement of community-based education in the medical curriculum. As a result of this experience, the faculty introduced a number of changes to the medical students' training programme. From the first year of enrolment, all medical students now have regular interaction with one of the designated primary care clinics as part of a new ASL programme called the Longitudinal Clinic Attachment Scheme (L-CAS). In addition, various opportunities have been introduced for critical reflection on clinical experience. As part of their final assessment, final-year students are now required to present a portfolio of clinical cases containing evidence of critical reflection. ${ }^{37}$

Using an ASL approach assisted the faculty to make an informed educational diagnosis and to adjust the training programme to better fit the learning needs of students and the service needs of the community.

\section{Acknowledgements}

We would like to thank the students for their contributions that enabled us to improve the Health and Health Systems module. The valuable comments of one of the anonymous peer reviewers are also acknowledged with appreciation.

\section{References}

1. De Villiers PJT, De Villiers MR. The current status and future needs of education and training in family medicine and primary care in South Africa. Med Educ. 1999;33(10):716-721.

2. Mash R, De Villiers MR. Community-based training in family medicine - a different paradigm. Med Educ. 1999;33(10):725-729.

3. Kent A, De Villiers MR. Medical education in South Africa - exciting times. Med Teach. 2007;29 (9):906-909.

4. Seggie JL. MB ChB curriculum modernisation in South Africa - growing doctors for Africa. AJHPE 2010;2(1):8-14.

5. Kaufman D. Applying educational theory in practice. BMJ. 2003;326:213-216.

6. Cameron D. Community-based education in a South African context: was Socrates right? SA Fam Pract. 2000;22(2):17-20.

7. ledema R, Degeling P, Briathwaite J, Kam Yin Chan D. Medical education and curriculum reform: putting reform proposals in context. Med Educ Online (homepage on the Internet). c2010. Available from: http://www.med-edonline.net

8. HPCSA. Education and training of doctors in South Africa. Undergraduate medical education and training. Guidelines by the Medical and Denta Professions Board. Pretoria: Health Professions Council of South Africa; 1999.

9. White paper on transformation of the health system. Government Gazette 382 (17910). Pretoria: Government Printers; 1997.

10. Coovadia $\mathrm{H}$, Jewkes R, Barron $\mathrm{P}$, et al. The health and health system of South Africa: historical roots of current public health challenges. Lancet. 2009;374(9692):817-834. Epub 2009.

11. Bender G. Pathways of change for integrating community service learning into the core curriculum. Education as Change. 2007;11(3):127-142.

12. Higher Education Quality Committee. Service-learning in the curriculum: a resource for higher education institutions. Pretoria: Council on Higher Education; 2006.
13. Republic of South Africa. Higher Education Act. Government Gazette 390 (18515). Pretoria: Government Printers; 1997

14. Osman R, Castle J. Theorising service-learning in higher education in South Africa. Perspectives in Education. 2006;24(3):63-70.

15. Bender G, Jordaan R. Student perceptions and attitudes about community service-learning in the teacher training curriculum. South African Journal of Education. 2007;631-654

16. O'Brien F. In pursuit of African scholarship: unpacking engagement. Higher Education. 2009;58:29-39.

17. Giles EG, Eyler J. The theoretical roots of service-learning in John Dewey: towards a theory of service-learning. Michigan Journal of Community Service Learning. 1994;1(1):77-85

18. Howard JPF. Academic service learning: a counternormative pedagogy. New Directions for Teaching and Learning. 1998;73:21-29.

19. Cashman SB, Seifer SD. Service-learning: an integral part of undergraduate public health. Am J Prev Med. 2008;35(3):273-278.

20. Elam CL, Musick DW, Sauer MJ, Skelton J. How we implemented a servicelearning elective. Med Teach. 2002;24(3):249-253.

21. Connor K, Seifer S. Reflection in higher education service-learning. Scotts Valley, CA: National Service-Learning Clearinghouse; 2005. c2010. Available from :http://www.servicelearning.org/instant_info/fact_sheets/he_facts/ he_reflection/

22. Mann K, Gordon J, MacLeod A. Reflection and reflective practice in health professions education: a systematic review. Adv in Health Sci Educ. 2009;14:595-621.

23. Sandars J. The use of reflection in medical education: AMEE Guide No. 44 Med Teach. 2009;31:685-695.

24. Driessen E, Van Tartwijk J, Dornan T. The self-critical doctors: helping students become more reflective. BMJ. 2008;336:827-830.

25. Faulner LR, McCurdy RL. Teaching medical students social responsibility: the right thing to do. Acad Med. 2000;75(4):346-350.

26. Coulehan J. Today's professionalism: engaging the mind but not the heart. Acad Med. 2005;80(10):892-898

27. Nyangairi B, Couper ID, Sondzabo NO. Exposure to primary healthcare for medical students: experiences of final-year medical students. SA Fam Pract. 2010;52(5):467-470.

28. Hunsaker ML, Glasser ML, Nielsen KM, Lipsky MS. Medical students' assessments of skill development in rural primary care clinics. Rural and Remote Health 6. [homepage on the Internet]. c2010. Available from: http:// www.rrh.org.au

29. Worley P, Lines D. Can specialist disciplines be learnt by undergraduates in a rural general practice setting? Preliminary results of an Australian pilot study. Med Teach. 1999;21(5);482-484.

30. Department of Health, South Africa. Standard treatment guidelines and essential medicines list for South Africa - primary health care level. $4^{\text {th }}$ ed. Pretoria: Department of Health; 2008.

31. Toole J, Toole P. Reflection as a tool for turning service experiences into learning experiences. In: Kinsey C, McPherson K, eds. Enriching the curriculum through service learning. Alexandria, VA: Association for Supervision and Curriculum Development; 1995:99-114.

32. Teekman B. Exploring reflective thinking in nursing practice. J Adv Nurs. 2000;31:1125-1135

33. Gustafsson C, Fagerberg I. Reflection, the way to professional development? $\mathrm{J}$ Clin Nurs. 2004;13:217-280.

34. Babbie E, Mouton J. The practice of social research. Cape Town: Oxford University Press; 2001

35. Morse JM, Richards L. Read me first for a user's guide to qualitative research Thousand Oaks, CA: Sage; 2002

36. Smith CS, Irby DM. The roles of experience and reflection in ambulatory care education. Acad Med. 1997;72(1):32-35

37. Burch VC, Seggie JL. Use of a structured interview to assess portfolio-based learning. Med Educ. 2008;42:894-900. 